\title{
Smoking in the home after the smoke-free legislation in Scotland: qualitative study
}

\author{
Richard Phillips, ${ }^{1}$ Amanda Amos, ${ }^{1}$ Deborah Ritchie, ${ }^{2}$ Sarah Cunningham-Burley, ${ }^{1}$ Claudia Martin ${ }^{3}$
}

EDITORIAL by Chapman RESEARCH pp 545, 549

${ }^{1}$ Public Health Sciences, Division of Community Health Sciences, University of Edinburgh, Medical School, Edinburgh EH8 9AG

${ }^{2}$ Nursing Studies, School of Health in Social Science, University of Edinburgh, Medical School

${ }^{3}$ Scottish Centre for Social Research, Edinburgh EH3 9AW

Correspondence to: A Amos amanda.amos@ed.ac.uk

BMJ 2007;335:553-7 doi:10.1136/bmi.39301.497593.55
This article is an abridged version of a paper that was published on bmj.com on 10 September 2007. Cite this version as: $B M J 10$ September 2007, doi: 10.1136/ bmj.39301.497593.55 (abridged text, in print: $B M$ J 2007;335:553-7).

\section{ABSTRACT}

Objective To explore the accounts of smokers and nonsmokers (who live with smokers) of smoking in their homes and cars after the Scottish smoke-free legislation; to examine the reported impact of the legislation on smoking in the home; and to consider the implications for future initiatives aimed at reducing children's exposure to secondhand smoke in the home.

Design and setting A qualitative cross sectional study involving semistructured interviews conducted across Scotland shortly after the implementation of the legislation on 26 March 2006.

Participants A purposively selected sample of 50 adults (aged 18-75) drawn from all socioeconomic groups, included smokers living with smokers, smokers living with non-smokers, and non-smokers living with smokers.

Results Passive smoking was a well recognised term. Respondents had varied understandings of the risks of secondhand smoke, with a few rejecting evidence of such risks. Children, however, were perceived as vulnerable. Most reported that they restricted smoking in their homes, with a range of restrictions across social classes and home smoking profiles. Spatial, relational, health, and aesthetic factors influenced the development of restrictions. Children and grandchildren were important considerations in the development and modification of restrictions. Other strategies were also used to militate against secondhand smoke, such as opening windows. The meaning of the home as somewhere private and social identity were important underlying factors.

Respondents reported greater restrictions on smoking in their cars. There were diverse views on the smoke-free legislation. Few thought it had influenced their smoking in the home, and none thought it had affected how they restricted smoking in their homes.

Conclusions These data suggest two normative discourses around smoking in the home. The first relates to acceptable social identity as a hospitable person who is not anti-smoker. The second relates to moral identity as a caring parent or grandparent. Awareness of the risks of secondhand smoke, despite ambivalence about health messages and the fluidity of smoking restrictions, provides clear opportunities for public health initiatives to support people attain smoke-free homes.

\section{INTRODUCTION}

Exposure to secondhand smoke is an important cause of premature mortality and morbidity, ${ }^{1-3}$ and children are more vulnerable than adults to the effects on health..$^{3-6}$ In 2003, over $80 \%$ of children aged
8-15 years in Scotland reported being exposed to secondhand smoke, ${ }^{7}$ and around $40 \%$ lived in a home with at least one smoker. The 2005 health education population survey found that less than half $(42 \%)$ of homes in Scotland had total smoking bans. ${ }^{8}$

Interventions to reduce children's exposure to secondhand smoke in the home have involved media campaigns or brief counselling sessions with parents and have had little success. ${ }^{910}$ This is perhaps not surprising as we know little about why people do or do not restrict smoking in their homes. ${ }^{4}$ Even less is known about influences on smoking restrictions in cars.

Two qualitative studies have generated insights about the factors that parents perceive as barriers to reducing their children's exposure to secondhand smoke in the home. ${ }^{11-13}$ These include difficulties associated with the supervision of children, lack of appropriate space to smoke outside the home, a desire to smoke in comfort or privacy, and concerns about the negative reactions of family and friends. ${ }^{12} 13$ These studies were limited in that they involved only disadvantaged smokers who had preschool children ${ }^{1213}$ and who wanted to increase home restrictions and lived in high rise accommodation. ${ }^{11}$

The introduction of legislation on smoke-free public places in Scotland in March $2006^{14}$ provided a unique opportunity to explore the social meaning of restrictions in the home. We carried out a qualitative study in Scotland shortly after the introduction of the legislation. We explored the accounts of smokers and non-smokers of the strategies they use to regulate smoking in their homes and cars; and examined the reported impact of the legislation on smoking in the home to identify potential enablers and barriers to reducing exposure in the home.

\section{METHODS}

Study design and participants - We carried out qualitative semistructured interviews with 50 smokers and nonsmokers who lived with smokers across Scotland. Respondents were purposively recruited from Wave 10 (September-November 2005) of the health education population survey. ${ }^{15} \mathrm{We}$ sampled on three characteristics: composition of smokers in the household, socioeconomic group (AB (professional, managerial and technical), C (skilled non-manual and manual), D (partly skilled and unskilled)), and sex (table). We invited 106 people to take part in the study. Fifty of the 54 eligible respondents were interviewed.

Interviews-Interviews were conducted between June and September 2006 in respondents' homes. We developed interview topic guides for the three types of participant: smoker living alone or with 
Box 1 Knowledge and understandings of risks of secondhand smoke

"Well they say it does, but I don't believe that is true. It is just one of these things I don't believe, they say people die from passive smoking, I don't accept it" 69 year old man, former smoker (C)

"I couldn't put an age on it because I don't think they should, even if they are older it has a less effect, then it is bad for them to see other people doing it because it means they want to do it themselves or they might want to try it" 49 year old woman, non-smoker (C)

another smoker, smoker living with a non-smoker, and non-smoker living with a smoker. Respondents used a day grid to describe a typical day in relation to smoking or exposure to smoke. ${ }^{1617}$ Smokers identified times and places when they smoked. Non-smokers identified when and where they were exposed to smoke. All respondents were asked to describe any smoking restrictions in their home or car, how they had developed and were maintained, and what might lead to breaches. Respondents were asked what they understood by passive smoking and whether they thought any people were more at risk. We sought respondents' views about and experiences of the smoke-free legislation and whether this had affected smoking in their home or their social life.

Analysis-We transcribed the tape recorded interviews and analysed transcripts thematically, moving from initial descriptive codes to more conceptual analytical coding. All authors were involved in the analysis, with at least two reading each transcript and agreeing on coding categories and themes. A modified grounded theory approach was taken whereby themes were revised iteratively as the fieldwork and analysis progressed. ${ }^{18}$

\section{RESULTS}

Knowledge and understanding of risks of secondhand smoke

Passive smoking was a well recognised term, though respondents' understanding of and views about the health risks varied. Most (36) indicated that they believed that exposure to secondhand smoke represented some form of risk. A smaller group of respondents (eight), all smokers, were more ambivalent about whether secondhand smoke was a health risk, yet reported a reluctance to expose children or grandchildren to secondhand smoke. A few respondents (six), all but one of whom were smokers, stated firmly that they did not believe that passive smoking was a health risk (box 1). Smokers who lived only with smokers or on their own were less likely than other respondents to believe that secondhand smoke was a health risk. There was no apparent difference in acceptance of risk by socioeconomic group.

Respondents drew on personal experiences around the visible effects of secondhand smoke on themselves and others, their knowledge about the health effects of active smoking and external sources of information including media coverage, and health professionals' advice. Many thought that children were particularly at risk because they were still developing. There were diverse views concerning when "vulnerable" children became less vulnerable (see box 1).

\section{Restrictions in the home}

Patterns of restrictions

There was a range of restrictions across all the household smoking profiles and socioeconomic groups (box 2). These restrictions were primarily spatial in naturerespondents described specific rooms or locations inside or outside the home where smoking was or was not permitted. These comprised a total ban inside the home (nine); smoking allowed in one specific room or at an outside door (10); smoking allowed in several rooms (25); no restrictions (six). Smokers who lived only with smokers or on their own were more likely to report having no restrictions, and respondents from socioeconomic group D were least likely to have a total ban.

Most respondents reported that they were concerned with the smell of tobacco smoke in their home and described actions to reduce or manage smoke or exposure in their homes (such as opening windows, lighting candles). All respondents with partial or no restrictions described how they would temporarily modify these in particular circumstances. For example, partial restrictions would become stricter in the presence of children and grandchildren, or relaxed if adult visitors were smokers.

\section{How and why restrictions were developed}

Respondents often had more than one reason for having restrictions on smoking (box 3). Aesthetic concerns were mostly about the smell of smoke. Health reasons related mainly to concerns about not exposing children and grandchildren and, in a few cases, adult non-smokers to the health risks of smoke. Respondents expressed concern about smoking in front of children, thus acting as a role model. Some also talked about pressure from children or from other family members not to smoke. Other less common health reasons included concerns around hygiene and safety.

Most respondents presented these changes as being unproblematic, with little conflict over decision

\section{Box 2 Patterns of home restrictions}

"I wouldn't even think about having a fag in the house, [name of daughter] comes first in that respect" 27 year old woman, smoker (D)

"There is a back door, there is a garden, this is where [kitchen] we should smoke and we don't allow [smoking] anywhere else in the house" 40 year old woman, smoker $(A B)$

"If we have got people here who don't smoke, we will be less inclined to smoke, certainly smoke less or maybe not at all" 59 year old man, smoker ( $A B)$ 
Box 3 How and why restrictions were developed

Respondent: "To smoke in front of young children nowadays? No, I would not advise it because they pick it up, the smoking, the habit, they see you doing it." Interviewer: "Are there any other reasons why you don't smoke in certain rooms?" Respondent: "No, just because of that, I respect her [wife who had quit smoking]" 55 year old man, smoker (C)

"My daughter spoke about 'We are starting a family,' and I said, 'Well for a better environment for them,' I says, 'Right, we will try and enforce this and we will try and go outside,' and we have stuck to it" 50 year old man, smoker (D)

making. No respondents reported that the smoke-free legislation had had an affect on their restrictions in the home.

Meaning of the home and smoker identity

Two factors emerged as important in how smoking restrictions were managed or moderated. These related to the meaning of the home and social identity. The home was seen as being a private space, a place of relaxation and comfort. This seemed to bring with it notions of choice about when and where respondents smoked in the home and about how others should respect their views. This discourse of privacy and individual choice also had a social dimension in that smokers and some former smokers expressed concern about how they would be perceived by family and friends if they restricted smoking. Concerns pivoted around being regarded as being anti-smoker, inconsiderate, and hypocritical. The smoke-free legislation was not presented as having moderated these concerns.

Beyond the home: smoking restrictions in cars

Forty respondents had access to a car. More respondents, including smokers, reported that they had total $(n=16)$ or partial $(n=19)$ restrictions on smoking in their car. Several said that partial restrictions could increase in the presence of children and non-smoking adults. No respondents in socioeconomic group D reported having total restrictions. The reasons for restrictions were similar to those in the home, with concerns around exposing children to secondhand smoke and aesthetic reasons. Smoking restrictions in the car seemed to be more robust than in the home, suggesting that the car occupies an intermediary position between public and private space; its confined nature also seemed to encourage stronger rules.

\section{Impact of the smoke-free legislation}

Respondents expressed various views about the smoke-free legislation, mostly positive. While most respondents highlighted positive effects (such as less smoky pubs, fewer children becoming future smokers), some were more ambivalent, with a few (all smokers) totally against the legislation. Negative views related primarily to the way the legislation had happened (such as inadequate opportunities for consultation) and thinking that the legislation had gone too far.

Most smokers thought that there had been little or no change in their level of smoking in the home since the legislation because their workplaces were already smoke-free, they did not go out much socially, or reductions in smoking had been easily accommodated. Several spoke about increased feelings of stigma when smoking in public and therefore the increased importance of being able to smoke in private. None of the non-smokers reported that their exposure to secondhand smoke in the home had increased. A few smokers expressed some sense that they had increased their smoking in the home or car, but this was mostly phrased in uncertain terms. They were also unsure about the level of any increase.

\section{DISCUSSION}

Growing awareness about the health risks of secondhand smoke combined with concerns about minimising the negative aesthetic aspects of smoking have led to increasing restrictions on smoking in homes and cars. ${ }^{3}$ Although all respondents said that they restricted smoking in their home at some time, many described how spatial restrictions on smoking were temporarily modified in some circumstances.

Respondents' accounts seemed to be underpinned by normative discourses of acceptable moral and social identities. An acceptable social identity pivoted around being seen to be a "considerate" smoker or non-smoker ${ }^{1920}$ who would appropriately modify their behaviour or restrictions for family and friends or on certain special occasions. Moral identities were constructed around being a caring parent, grandparent, or adult. ${ }^{13}$ The presence of children was cited as the main reason for both total bans and temporarily

Details of participants interviewed about smoking in their homes

\begin{tabular}{|c|c|c|c|c|c|c|c|}
\hline \multirow[b]{2}{*}{ Socioeconomic group* } & \multicolumn{2}{|c|}{$\begin{array}{l}\text { Smokers living alone or with } \\
\text { smokers only }\end{array}$} & \multicolumn{2}{|c|}{$\begin{array}{l}\text { Smokers living with any non- } \\
\text { smokers }\end{array}$} & \multicolumn{2}{|c|}{$\begin{array}{l}\text { Non-smokers living } \\
\text { with any smokers }\end{array}$} & \multirow[b]{2}{*}{ Total } \\
\hline & Men & Women & Men & Women & Men & Women & \\
\hline$A-B$ & 2 & 2 & 1 & 0 & 0 & 3 & 8 \\
\hline $\mathrm{C} 1-\mathrm{C} 2$ & 5 & 7 & 5 & 3 & 5 & 5 & 30 \\
\hline D & 4 & 4 & 1 & 2 & 0 & 1 & 12 \\
\hline Total & 11 & 13 & 7 & 5 & 5 & 9 & 50 \\
\hline
\end{tabular}


Box 4 Enablers and barriers to creating smoke-free homes

Enablers include:

- The increasing level of restrictions and the reported modification of partial or no restrictions in some circumstances

- The higher level of restrictions in cars

- Increasing awareness of the risks of secondhand smoke, particularly in relation to children

- Concerns about children and grandchildren not becoming smokers

- Desire to be seen as behaving in morally and socially acceptable ways

- Other attempts, both aesthetic and health related, to moderate or remove the perceived negative aspects of smoke in the home

- Social norms about the unacceptability of smoking in the home among family and friends, including pressure from children

Barriers include:

- Limited understanding of and resistance to messages about the health risks of secondhand smoke

- Beliefs about the effectiveness of ways of removing or managing secondhand smoke in the home

- The need to smoke and smoker identity

- The home (and car) perceived as a private space, protected from public controls and sanctions

- Social norms among family and friends about the acceptability of smoking in the home

increasing restrictions. In addition to concerns about reducing children's exposure to the possible health risks of secondhand smoke were considerations about the future consequences of children seeing adults smoke. The desire to be seen to act in socially and morally acceptable ways seemed to be tempered by other imperatives and needs. These included the need to smoke, the desire to smoke in comfort and

\section{WHAT IS ALREADY KNOWN ON THIS TOPIC}

Exposure to secondhand smoke is an important cause of morbidity in children, and the main source of exposure is in the home

Little is known about why people do or do not restrict smoking in their homes and the enablers and barriers to reducing children's exposure in the home

\section{WHAT THIS STUDY ADDS}

Most people restrict smoking in their home but the extent and likely effectiveness vary. Spatial, health, relational, and aesthetic factors are influential and protection of children and grandchildren is a priority

There were diverse views about the smoke-free legislation; few thought it had influenced their smoking in the home

Awareness of the risks of secondhand smoke, despite ambivalence about health messages and the fluidity of smoking restrictions, provides opportunities for public health initiatives to support people to achieve smoke-free homes private, understandings of the risks of secondhand smoke, and social norms.

While some respondents were convinced that secondhand smoke was a health risk others were much less certain, and some indicated a level of resistance to such messages. This is perhaps not surprising given that evidence and education about the health risks of secondhand smoke is relatively recent compared with that on active smoking. Some smokers might resist messages that could have consequences for their smoking, home lives, and routines. Ambivalence about health messages needs also to be understood as a more general phenomenon, relating to a distrust of scientific knowledge and resistance to externally imposed restraints on individual behaviours.

\section{Strengths and limitations}

One strength of our study was the diverse range of respondents in terms of age, socioeconomic group, location, and household smoking profile. This meant that it was not possible to explore in depth the views and experiences of certain groups who may face particular challenges around addressing secondhand smoke in the home, ${ }^{13}$ such as those living in homes where space is restricted or lack outside space. ${ }^{11}$ Another limitation was the retrospective nature of the study, which may have made it difficult for respondents to assess the impact of the legislation on their knowledge, attitudes, and behaviour. It may also be that such changes take longer to occur than the period covered in this study.

\section{Implications}

Reducing secondhand smoke in the home and car requires a coordinated approach involving national and local action aimed at reducing smoking among adults and protecting children and non-smokers from secondhand smoke in smoking homes. ${ }^{6}$ Comprehensive smoke-free legislation can help achieve these aims. ${ }^{3}$ Our findings indicate that smoking restrictions in the home are shaped by a range of sociocultural influences and other factors that create enablers, and barriers for future public health initiatives on this issue (box 4). Initiatives to reduce secondhand smoke in the home could include media campaigns and tailored advice and support for individuals from health and other professionals on how to develop more effective smoke-free strategies in the home and car. ${ }^{6}$

We thank Irene Miller and Fiona Rait, who undertook some of the interviews; Agnes McGowan, who provided "breathe easy" materials; and Sally Haw for advice and support. We also thank all the respondents for giving their time to this study.

\section{Contributors: See bmi.com}

Funding: NHS Health Scotland and the Scottish Executive. The views expressed in this paper are those of the authors and not necessarily those of the funders.

Competing interests: None declared.

Ethical approval: The study complied with the code of practice on ethical standards for social research involving human respondents operating in public health sciences at Edinburgh University.

Provenance and peer review: Non-commissioned; peer reviewed. 
1 Hole D. Passive smoking and associated causes of death in adults in Scotland. Edinburgh: NHS Health Scotland, 2004.

2 Jamrozik K. Estimate of deaths attributable to passive smoking among UK adults: database analysis. BMJ 2005 doi: 10.1136/ bmj.330.7495.0.

3 Royal College of Physicians. Going smoke-free: the medical case for clean air in the home, at work and in public places: a report on passive smoking by the Tobacco Advisory Group of the Royal College of Physicians. London: Royal College of Physicians of London, 2005.

4 Ashley MJ, Ferrence R. Reducing children's exposure to environmental tobacco smoke in homes: issues and strategies. Tob Control 1998;7:61-5.

5 Jones S. Smoking and reproductive life. London: British Medical Association, 2004.

6 Muller T. Breaking the cycle of children's exposure to tobacco smoke. London: British Medical Association, 2007.

7 Bromley C, Sproston K, Shelton N, eds. The Scottish health survey 2003: summary of key findings. Edinburgh: Scottish Executive Health Department, 2005.

8 Scottish Executive. Smoking in public places-November 2005 omnibus survey report. Edinburgh: Scottish Executive, 2006.

9 Hovell MF, Zakarian JM, Wahlgren DR, Matt GE. Reducing children's exposure to environmental tobacco smoke: the empirical evidence and directions for future research. Tob Control 2000;9(suppl 2): ii40-7.

10 Roseby R, Waters E, Polnay A, Campbell R, Webster P, Spencer N. Family and carer smoking control programmes for reducing children's exposure to environmental tobacco smoke. Cochrane Database Syst Rev 2002;(3):CD001746.
11 Hill L, Farquharson K, Borland R. Blowing smoke: strategies smokers use to protect non-smokers from environmental tobacco smoke in the home. Health Prom I Australia 2003;14:196-201.

12 Robinson J, Kirkcaldy A. You think that I'm smoking and they're not: why mothers still smoke in the home. Soc Sci Med 2007 doi: 10.1016/j.socscimed.2007.03.048.

13 Robinson J, Kirkcaldy A. Disadvantaged mothers, young children and smoking in the home: mothers' use of space within their homes. Health Place 2007 doi: 10.1016/j.healthplace.2007.03.001.

14 Scottish Executive. The Smoking, Health and Social Care (Scotland) Act 2005. Part 1. Edinburgh: Stationery Office, 2005.

15 Haw SJ, Gruer L, Amos A, Currie C, Fischbacher C, Fong GT, et al. Legislation on smoking in enclosed public places in Scotland: how will we evaluate the impact? J Public Health 2006;28:24-30.

16 Bancroft A, Wiltshire S, Parry O, Amos A. "It's like an addiction first thing ... afterwards it's like a habit": daily smoking behaviour among people living in areas of deprivation. Soc Sci Med 2003;56:1261-7.

17 Wiltshire S, Bancroft A, Parry O, Amos A. "I came back here and started smoking again": perceptions and experiences of quitting among disadvantaged smokers. Health Educ Res 2003;18:292-303.

18 Glaser BG, Strauss AL. The discovery of grounded theory: strategies for qualitative research. New York: Aldine Publishing, 1967.

19 Poland B, Frohlich K, Haines RJ, Mykhalovskiy E, Rock M, Sparks R. The social context of smoking: the next frontier in tobacco control? Tob Control 2006;15:59-63.

20 Poland B. The "considerate" smoker in public space: the micropolitics and political economy of "doing the right thing." Health Place 2000;6:1-14

Accepted: 31 July 2007
Royal Shrewsbury Hospital,

Shrewsbury SY3 8XQ

Correspondence to: A Leitch, Anaesthetic Department,

Southampton General Hospital,

Tremona Road,

Southampton S016 6YD

AndrewLeitch@doctors.org.uk

BMJ 2007;335:557

doi:10.1136/bmi.39020.710602.47

\section{DRUG POINTS}

\section{Calculate the QT interval in patients taking drugs for dementia}

\section{Andrew Leitch, Peter McGinness, David Wallbridge}

A 76 year old woman was referred acutely after two syncopal episodes. She had a history of depression and Alzheimer's disease. No cardiac problems were reported. On admission her blood pressure was 160/112 mm Hg but she had a sinus bradycardia (42 beats $/ \mathrm{min}$ ) and the cardiac monitor showed paroxysmal ventricular tachycardia (torsade de pointes). The resting electrocardiogram showed gross prolongation of the QT segment (corrected QT interval 590-777 ms). She was treated with intravenous magnesium, an infusion of isoprenaline, and then temporary cardiac pacing $(100$ beats $/ \mathrm{min})$ with complete suppression of the dysrhythmia. Initial biochemistry (serum potassium, magnesium, and calcium) gave normal results, and the 12 hour troponin $\mathrm{T}$ $(0.06 \mu \mathrm{g} / \mathrm{l})$ was borderline. Her drug history included donepezil $10 \mathrm{mg}$ (for two years), omeprazole $20 \mathrm{mg}$, escitalopram $10 \mathrm{mg}$, and propranolol $80 \mathrm{mg}$ (started five days before admission for an essential tremor and anxiety symptoms). Donepezil, escitalopram, and propranolol were discontinued, and the QT interval normalised (corrected QT interval $436 \mathrm{~ms}$ ). Depressive symptoms were treated with mirtazipine, and the patient required nursing home care. Subsequent review of the notes showed that a normal electrocardiogram had been obtained 18 months previously during investigation of palpitations.

About 3\% of prescriptions in the United Kingdom represent non-cardiac drugs with proarrhythmic potential. ${ }^{1}$ The drugs associated with prolonged QT interval include antiarrhythmics, antihistamines, antimicrobials, tricyclic antidepressants, and selective serotonin re-uptake inhibitors. ${ }^{2}$ QT prolongation with acetylcholinesterase inhibitors for dementia (rivastigmine) has been reported. ${ }^{3}$ Adverse effects reported for donepezil include bradycardia (uncommon) and heart block (rare). The data sheet for donepezil refers to "potential for synergistic activity with ... betablocking agents which have an effect on cardiac conduction." Escitalopram is very rarely associated with prolongation of the QT interval. It inhibits CYP 2D6, the enzyme responsible for the metabolism of donepezil, and escitalopram metabolism is inhibited by omeprazole.

Doctors need to be aware of potential drug interactions with donepezil. Calculating the corrected QT interval may be a life saving arithmetical exercise when elderly patients are treated for dementia.

\section{Funding: None.}

Competing interests: None declared.

1 De Ponti F, Poluzzi E, Montanaro N, Ferguson J. QTc and psychotropic drugs. Lancet 2000;356:75-6.

2 Medicines and Healthcare Products Regulatory Agency. Adverse drug reactions online information tracking: rivastigmine. www.mhra.gov. uk/home/groups/public/documents/sentineldocuments/ dap 1130236048936.pdf

3 Yap YG, Camm AJ. Drug induced QT prolongation and torsade de pointes. Heart 2003;89:1363-72. 